Ebenso gilt es für Königsberg und für Bonn, wenn man unsere Versuche des vorigen Jahres in Betracht zieht.

$\mathrm{Zu}$ Versuchen iiber Geschlechtsursachen können also nur solche Raçen, resp. Varietäten des braunen Grasfrosches gebraucht werden, die wie die Königsberger fast keinen irregularen Hermaphroditismus aufweisen.

\title{
Ueber die parthenogenetische Furchung der Eier der Amphibien.
}

Von

E. Pflüger.

Nicht wenigen Forsehern der neueren Zeit scheint das grosse Geheimniss der Zeugung dadurch seiner Lösung wesentlich näher geriickt, dass die Eier einiger Thiere angeblich auch ohne Befruchtung sich entwickeln und die Eier Vieler wenigstens die Entwickelung anfangen, der Same also den Ablauf der Processe nur ein wenig zn unterstützen scheint.

Die spontane oder parthenogenetische, d. h. ohne Befruchtung eintretende Furchung der Eier wird für viele Thiere und auch für die Batrachier von hochangesehenen Forschern behanptet. Da ich über diesen Punkt volle Gewissheit haben musste für meine Versuche über Bastardzengung, untersuchte ich den Gegenstand genauer. Ich will zuerst diejenigen Thatsachen darlegen, deren Beachtung bei den Forschungen jener Gelehrten vermisst wird.

Spallanzani ${ }^{1}$ ) zeigte, dass 3 Gran - also ca. 4-6 Tropfen Same vom Frosch gelöst in $1 / 2$ Liter Wasser genügten, um alle Eier von 50 Froschweibchen, d. h. sehr viele Tausende, zu befruchten. Das Wasser war nachher noch immer fähig, nene Eier zu beleben. Wenn Spallanzani 3 Gran Same, also einige Tropfen in 22 Pfund Wasser vertheilte, so zeigte dieses Wasser noch immer befruch-

1) Spallanzani, Versuche über die Erzeugung der Thiere und Pflanzen. Deutsch. 1786. p. 188. 
tende Kraft ${ }^{1}$ ). Derselbe Forscher ermittelte ferner, dass das Wasser aus einem Gefässe, in dem ein Paar Frösche gelaicht hatten, befruchtete ${ }^{2}$ ). Das Alles ist uns heute nicht mehr wunderbar, seitdem wir wissen, dass ein Spermatozoon, d. h. ein in Wasser unlöslicher, unendlich kleiner fester Körper zur Befruchtung eines Eies geniugt, und dass stets bei der Befruchtung, was obiger Versuch Spallanzani's in der denkbar auffallendsten Art beweist, ein ganz unermesslicher Ueberschuss von Spermatozoen vom Männchen ibber den Laich ergossen wird. Wir können heute mit aller Bestimmtheit behaupten, dass keine noch so weit getriebene Verdünnung des Froschsamens mit Wasser die befruchtende Kraft absolut aufhebt. Die Verdünnung hat nur zur Folge, dass der Samenfaden das Ei, das in das besamte Wasser gelegt wurde, einfach nicht trifft, weil er zu weit von ihm entfernt und bei seinen Bewegungen nicht planmässig dem Ei zugeführt wird. Denn offenbar besteht keine Anziehung zwischen Samen und Ei auf Entfernungen. Sobald aber ein einziges in einer selbst unendlichen Wassermasse suspendirtes lebendiges Spermatozoon des Frosches ein reifes lebendiges Froschei trifft, vollzieht sich die Befruchtung. Zur Zeit, wo die Froschweibchen reife Eier im Uterus beherbergen, finden sich auch öfter schon Paare, welche bereits abgelaicht haben, so dass das Wasser der Tümpel besamt ist. Auch selbst wenn die Weibchen noch nicht geboren, ist ein Umstand zu erwägen, den ich oft genug bemerkt habe. Die brünstigen Männchen sind zu dieser Zeit so reizbar, dass die geringfiigigste Veranlassung ausreicht, selbst bedeutende Fntleerung des Samens aus den strotzend gefïllten Samenblasen nach Aussen zu bewirken.

Sehr oft stösst das Männchen, wenn das sich umarmt haltende brünstige Paar eben gefangen oder gefasst wird, seinen ganzen Samen aus, so dass die Haut des Weibchens davon trieft. Man muss also nicht glauben, dass keine Samenentleerungen der Männchen vor der Ausstossung der Eier vorkämen. Schon Roesel von Rosenhof ${ }^{3}$ ) hat diesen Punkt in genïgender Weise festgestellt. Er erzählt: „Nachdem ich meine Frösche etliche Tage betrachtet hatte, ohne eine sonderliche Aenderung an ihnen wahrzunehmen, so merkte

1) Spallanzani, a. a. 0. p. 175 .

2) Spallanzani, a. a. 0. p. 320 .

3) J. A. Roese1 von Rosenhof, Naturgeschichte der Frösche Deutschlands. Neue Auflage von 1815. Vorrede von 1753. p. 5. 
ich endlich, dass sie unruhiger wurden. Das Männlein grunzte bei dieser Unruhe manchmal wie ein Schwein, und das Weiblein ging auf und nieder. Da mich nun dieses bewog, genauer auf sie Achtung zu geben, so sah ich, dass ein Männlein bei dieser Unruhe zu verschiedenen malen eine Feuchtigkeit aus seinem Hinterleibe von sich gab, welche ich deswegen fiur den Samen hielte, weil sie das Wasser, in welchem die Frösche schwammen, ganz trüb machte. Bald darauf verliess er sein Weiblein. Als ich nun zwölf Stunden lang constant gewartet hatte, ob dieses nicht seinen Laich ron sich geben wïrde: so öffnete ich beide und fand, dass in dem Weiblein die Mutter zum Theil mit Eiern angefiullt war, zum Theil aber selbige noch in dem Eierstock und in den Eiergängen steckten; in dem Männlein hingegen waren die Samenbläslein, die sonst zu dieser Zeit sehr angefüllet sind, leer. Die Eier, die ich in der Matter gefunden hatte, legte ich in neues Wasser, erhielt aber daraus keine Wiirmer (Quappen); sodass also dieser Frösche Paarung unfruchtbar gewesen ist. - - An einem anderen Paare hingegen ging es ebenso, wie ich bereits oben gemeldet habe, dass nämlich das Männlein seinen Samen von sich gab und darauf das Weiblein verliess. Dies aber fing erst nach sechszehn Stunden an zu laichen, und hierbei ging es so langsam zu, dass selbiges innerhalb vierundzwanzig Stunden kaum erst die Hälfte seiner Eier von sich gegeben hatte, worauf es starb. Der Laich schien zwar Anfangs, gleich einem befruchteten, aufzulaufen, er verdarb aber nachgehends doch, ohne dass ich ein einziges Würmlein (Larve) daraus erhielt; dies macht mich glauben, dass die Paarung der Frösehe nicht fruchtbar sei, wenn sie sich endigt, ehe die Eier alle in die Mutter getreten sind." Richtiger: ehe alle Eier vom Weibchen nach Aussen entleert sind.

Setzt man also irgend ein frisch gefangenes Weibchen isolirt in ein Gefäss mit Wasser, so kann das letztere durch am Weibchen noch hangenden Samen befruchtungsfahig werden. Nun muss man nicht glauben, dass der Same in dem Wasser so bald abstirbt. Sehon Spallanzani zeigte ${ }^{1}$ ), dass mit Wasser verdünntes Sperma vom Frosch (3 Gran auf $1 / 2$ Liter) seine Kraft bei $17-19^{\circ}$ R. 35 Stunden, in einer Eisgrube 57 Stunden bewahrte. Ich habe mich auch iiberzengt, dass mit viel Wasser verdünntes Sperma des braunen Grasfrosches seine befruchtende Kraft viele Stunden behauptet.

1) Spallanzani, a. a. O. p. 189. 
Wenn man also ein frisch gefangenes isolirtes, brünstiges Froschweibchen selbst 24 Stunden in einem Gefässe sitzen hat, ist man nicht absolut sicher, dass ihm nicht noch wirksamer Same anhängt.

Same aber, der längere Zeit im Wasser suspendirt war und sich dem Absterben nähert, vermag zwar noch zu befruchten, aber es kommt nur zu den ersten Furchungen: das Ei stirbt ab. Diese Erscheinung der stehenbleibenden Entwicklung ist besonders geeignet, den Glauben zu bestärken, dass es sich um keine ächte, durch Befruchtung veranlasste Furchung gehandelt habe. Ganz ähnlich wie die durch absterbenden Samen befruchteten verhalten sich uiberreife Eier nach meiner Erfahrung, die sich auf viele Versuche stïtzt. Sie furchen sich melirmals und - verderben dann.

Ich verfuhr zur Prüfung der Frage demnach folgendermaassen: Die Froschweibchen wurden in besonderen Gefässen, nachdem sie von den Männchen isolirt waren, wiederholt mit immer erneutem Wasser übergossen, um allen anhängenden Samen fortzuschwemmen und zwei Tage darauf zum Versuche verwandt. Das zu benutzende Wasser, welches die Eier aufnehmen sollte, war abgekocht und wieder abgekühlt, alle Instrumente, mit denen die Operation am Thiere ausgeführt werden sollte, längere Zeit in siedendem Wasser erhitzt. Wenn ich dann die Eier aus dem Uterus in mit jenem unschädlich gemachten Wasser gefüllte Uhrschälchen brachte, trat niemals unter Tausenden von Eiern die Spur einer Furchung ein. Jedesmal fügte ich am Schlusse aller Operationen einem Uhrglas eine Spur von Same zu - und hier entwickelten sich natürlich wie gewöhnlich fast alle Eier.

Sehr oft habe ich diesen Versuch mit den Eiern des braunen Grasfrosches angestellt, einmal auch mit denen von Rana esculenta, einige Mal mit denen von Bufo cinereus und Triton eristatus, am häufigsten mit denen von Triton alpestris und wiederholt mit denen von Triton taeniatus. Niemals furchen diese Eier sich ohne Befruchtung.

Bemerken muss ich, dass, weil Spallanzani die künstliche Befruchtung der aus den Eileitern der Tritonen künstlich entnommenen Eier nicht bewerkstelligen konnte, ich glücklicher gewesen bin, selbstverständlich indem ich die der Kloake nächsten Eier als Controle bei Seite setzte und sie nicht mit Sperma in Berührung brachte. Die Letzteren durften sich nicht entwickeln, also 
nicht bereits ursprünglich befruchtet gewesen sein, wenn der Versuch Etwas beweisen sollte. Denn bekanntlich werden ja die Eier der Tritonen nicht ausserhalb des Körpers wie bei den meisten Fröschen befruchtet.

Somit steht fest:

Kein Batrachierei furcht sich ohne Befruchtung.

\section{Wirkt der Saft der Hoden nicht brünstiger Männchen befruchtend?}

Von

E. Pflinger.

Bei vielen Thieren wiederholt sich die Brunst nur einmal jedes Jahr, dauert kurze Zeit, um dann spurlos zu verschwinden. Nachdem das Männchen des braunen Grasfrosches aus dem Winterschlafe erwacht ist, erscheint in dem ausgehungerten Thiere selbst, wie behauptet wird, im thanenden Eise beim herannahenden Frühjahr eine intensive Brunst, die etwa 1 Monat anhält. So heftig ist dieselbe, dass das Männchen sich mit Krötenweibchen, wie ich und Andere 1) vielfach gesehen haben, begattet. Rösel ${ }^{2}$ ) berichtet, dass solche Männchen selbst Männchen und todte Weibchen brïnstig umarmen. Spallanzani ${ }^{3}$ ) beobachtete Aehnliches bei den Krötenmännchen.

Die Brunst vieler Batrachier ist so gross, dass z. B. der braune Grastrosch nach der Entfernnng des Gehirns die Begattung fortsetzte. Spallanzani ${ }^{4}$ ) behauptet, er habe einen geköpften

1) Rösel von Rosenhof, Naturgeschichte der Frösche, p. 5.

2) Rösel a. a. 0 .

3) Spallanzani, Versuche über die Erzeugung der Thiere und Pflanzen. 1786. p. 319.

4) Spallanzani a. a. 0. p. 93,321 u. 322 . 